\title{
Future Electricity Production from Geothermal Resources Using Oil and Gas Wells
}

\author{
Asif Mehmood*, Jun Yao, Dong Yan Fun \\ China University of Petroleum (East China), Qingdao, China \\ Email: *asifupc@yahoo.com
}

How to cite this paper: Mehmood, A. Yao, J. and Fun, D.Y. (2017) Future Electricity Production from Geothermal Resources Using Oil and Gas Wells. Open Journal of Yangtze Gas and Oil, 2, 191-200. https://doi.org/10.4236/ojogas.2017.24015

Received: March 19, 2017

Accepted: October 24, 2017

Published: October 27, 2017

Copyright $\odot 2017$ by authors and Scientific Research Publishing Inc. This work is licensed under the Creative Commons Attribution International License (CC BY 4.0).

http://creativecommons.org/licenses/by/4.0/

(c) (i) Open Access

\begin{abstract}
Various under-developed countries are not capable to accomplish its domestic energy requirements and are undergoing sensitive energy crises. Electricity Sector has been most suffered due to the energy shortage. Geothermal power production is capable to fulfill the electricity demand of different countries. Geothermal power plant can use water from an aquifer at moderately higher temperature and produce power using dry steam, flashing or binary cycle. Traditionally, geothermal energy has been exploited in places with plentiful hot water at relatively shallow depth. There are several high gradient geothermal resources available in the world but without the presence of aquifer it is impossible to utilize these resources. It is still unknown how to generate power by using dry rock resources. We aimed to focus on the way to generate electricity by utilizing the dry rock resources. This way of electricity generation will be cost effectively and can produce electricity on constant or permanent basis. Current study lead a new direction that how abandoned oil and gas wells are helpful to overcome the energy crises and have ability to generate the cheap electricity for a long term period. This study discusses the power generation system for commercial electricity production. Three different source temperatures $\left(142^{\circ} \mathrm{C}, 157^{\circ} \mathrm{C}\right.$, and $\left.177^{\circ} \mathrm{C}\right)$ were considered. Optimal working fluid and optimal design that improve the performance of plant are determined. Here we saw that a 12 inch double-pipe heat exchanger, which penetrates to a depth of $3 \mathrm{~km}$, could extract sufficient energy to drive a $3.2 \mathrm{MW}$ turbine generator system.
\end{abstract}

\section{Keywords}

Geothermal Energy, Oil and Gas Wells, Hot Dry Rock, Electricity Production

\section{Introduction}

Current energy demand of the world is increasing but the conventional fossil 
fuel is not appropriate and economical for energy generation. The International Energy Agency (IEA) 2014 world energy outlook suggests at least half of the entire growth in global production should be met by renewable energy sources for the period leading to 2040 [1] [2]. Current energy markets are not necessarily designed to suitably integrate renewable energy as part of a mix with fossil fuel generation while networks themselves face technical issues as the penetration of renewable energy increases [1] [2]. While more conventional technologies of wind, solar photovoltaic are expected to take a leading role in the renewable energy technology. Current energy markets are not necessarily designed to suitably integrate renewable energy as part of a mix with fossil fuel generation while networks themselves face technical issues as the penetration of renewable energy increases [1] [2]. These technical issues are the variability and uncertainty of renewable energy generation, reserves management, market design, flexible generation source, operational practices and impacts to fossil-fueled generators. To defeat this issue, the future energy system, which exploits energy from different resources, must work together to even out the variation in available sources of renewable energy.

Geothermal refers to existing heat energy in deep rock and sedimentary basins. These formations can provide hot fluid that can be utilized to produce electricity by using work producing machine. Depending on the situation of geothermal fluid in the reservoir, different power producing cycles may be used, including flash-steam, binary, direct steam and combined flash-binary cycles. Simply it is proved that binary power plant have greater efficiencies than flashing plants for liquid-dominated low temperature resources in the range of $100^{\circ} \mathrm{C}$ and $170^{\circ} \mathrm{C}$. Binary system is not open to environment, geothermal water is reutilized, no pollution is released in the environment [1]. More information on the operation of the commonly used geothermal units and its thermodynamic process can be found in [3]. The geothermal power unit occupied less area comparatively to the solar power plant. In addition, geothermal power plants produce a high percentage of the freshwater needed in their cooling system. For these reasons, the power industry has increasingly added geothermal power units in their electricity power production mix, worldwide, and trend show they will add more in the future [3] [4] [5].

The electricity power production from geothermal energy has been continuously increasing since 1970s. In 2014 twenty four countries were using electric power from geothermal energy with the installed capacity of 12,800 MW [3]. Geothermal energy provides approximately $0.4 \%$ of the world electricity energy production [3] [4] [5]. The dry rock resources are broadly distributed on the earth and not widely utilized at present because these resources do not have aquifer. Most of the high temperature geothermal resources have been utilized but major expansion in the use of geothermal energy will occur with the utilization of dry rock resources. This study indicates the worldwide trend of geothermal energy consumption as well as engineering systems for the extraction of 
geothermal energy from hot, dry rock sources.

\section{Geothermal Resources Utilization in the World}

First geothermal power plant was established in Larderello (Italy), 1904.The planning, construction and commissioning of geothermal power plant accelerated appreciably from 1975 to 1985 and significant rise of fossil fuel price and depletion of hydrocarbon reserves has increased its production demand, between 2002 and 2008. Figure 1 shows the capacity of geothermal power plant in USA and globally [6] [7]. The following factors drive the development of geothermal energy exploitation worldwide.

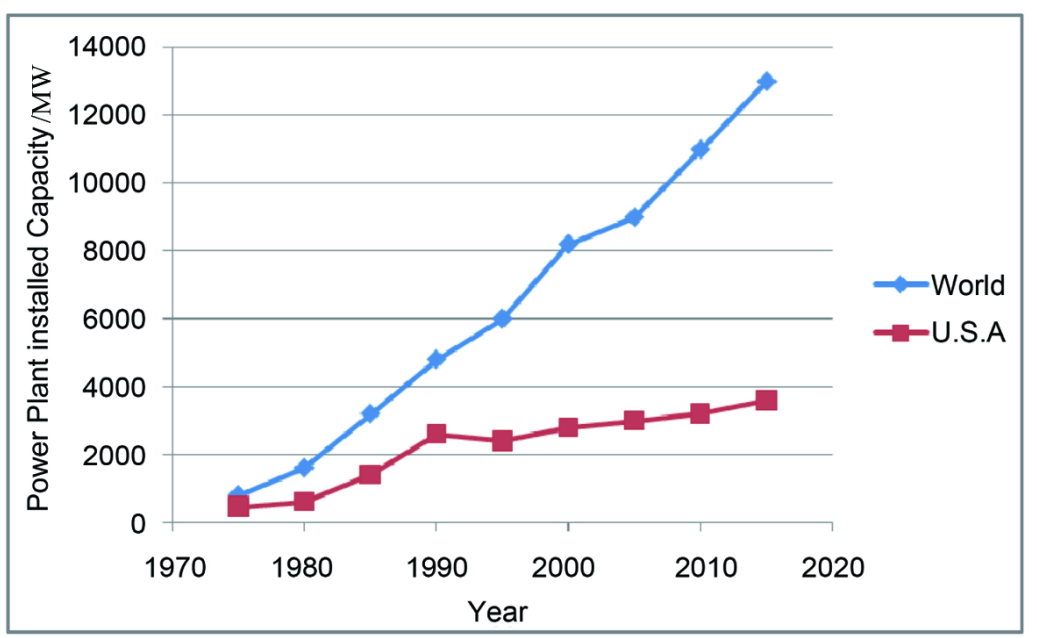

(a)

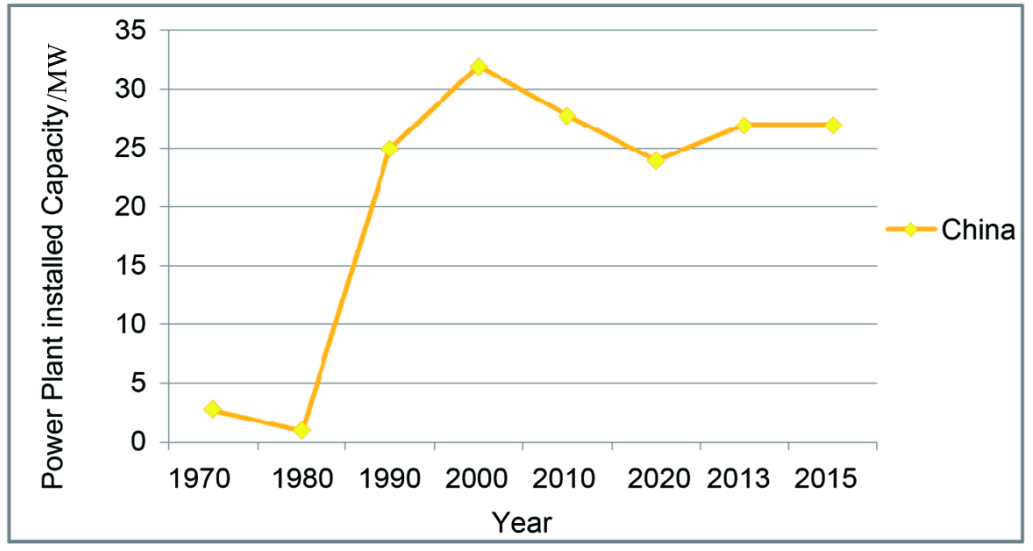

(b)

Figure 1. (a) Global and USA geothermal power installed capacity [3] [4]; (b) China geothermal power installed capacity [8].

1) Low capital cost of geothermal power plants in comparison to the solar, fossil and nuclear power plants.

2) Geothermal power technology is old and broadly available in the world and can be produced continuously. 
3) The comparatively low cost of electric energy produced.

4) The worldwide enlarged attentiveness of the harmful effects of the fossil fuels and $\mathrm{CO}_{2}$ in the environment.

5) Geothermal technology is based on the fossil fuel technologies that are older and well-known.

One of the remarkable trends in the figure can be seen that during time 1985-2000 the geothermal installed capacity more than doubled globally, from $3260 \mathrm{MW}$ to $8150 \mathrm{MW}$ [9]. The types of power plants that generate electric power from geothermal energy are shown in Figure 2. It can be observed in this figure that binary units, which contributed $2 \%$ of geothermal power in 1990, having the significant rate of enlargement between 2000 and 2014 [4].

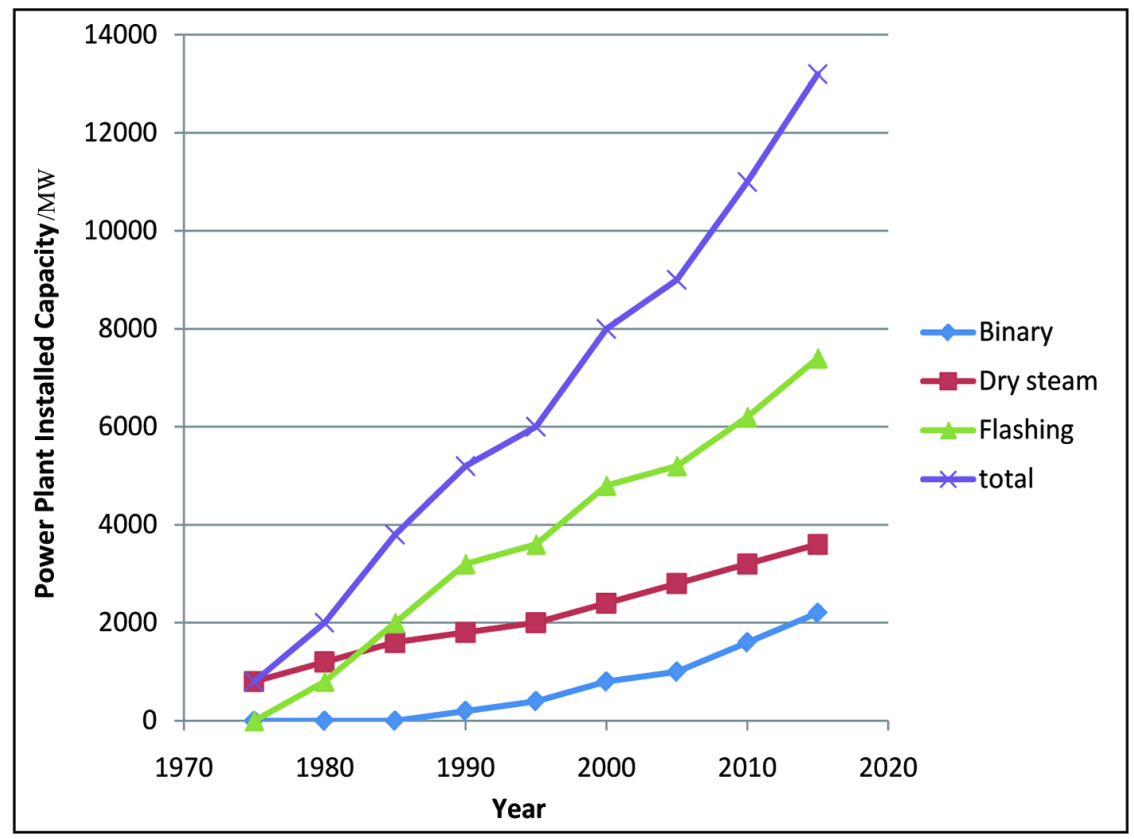

Figure 2. Globally installed capacity by type of geothermal power plant. Data from [3] [4].

The second curve in Figure 1 shows the installation capacity of geothermal power plant in USA. The figure shows smaller increase, around $17 \%$ in geothermal plant capacity between 1990 and 2005. Between 2005 and 2014 there was an accelerated increase of geothermal units and the geothermal power plant capacity of the country which is increased by $24 \%$. This increase is principally motivated by the utilization of lower temperature resources $\left(\mathrm{T}<180^{\circ} \mathrm{C}\right)$.

As regards the non OECD (Organization for Economic Cooperation and Development) countries, identified potential estimates of geothermal resources in the East African Rift System having range between 10,000 and 20,000 MW and remain mostly undeveloped. In Asia's geothermal sector as well as Philippines and Indonesia offer incentives for the growth of geothermal resources and are accelerating the construction of geothermal power plant. Indonesia contains just 
about 27,510 MW potential of geothermal resources which is largest potential in the world. The almost all of countries in America have developed small frication of geothermal resources for production of power. In 2011 Europe had installed capacity of $1600 \mathrm{MW}$ for geothermal energy. Europe and Italy is the market leader with over $50 \%$ of the European electricity capacity. Iceland derives $25 \%$ of its electricity and $90 \%$ of its heating from geothermal resources and they are investing more to construct the power plants for electricity production.

Current geothermal power plant utilizes water of an aquifer, which is located at high geothermal gradient areas having depths between $1 \mathrm{~km}$ and $3 \mathrm{~km}$. These resources are generally located on the tectonic boundaries of tectonic plate. Significant power generation from geothermal energy is currently constrained to those countries that are very close to tectonic plate boundaries. These countries and their installed geothermal power capacity have been listed in the Table 1 that is given below.

Table 1. Leading countries and installed geothermal capacity in MW, in 2014 [3].

\begin{tabular}{cc}
\hline Country & Installed Capacity/MW \\
China & 25 \\
Costa Rica & 205 \\
EI Salvador & 45 \\
Guatemala & 660 \\
Iceland & 1380 \\
Indonesia & 940 \\
Italy & 540 \\
Japan & 600 \\
Kenya & 1005 \\
Mexico & 970 \\
New Zealand & 88 \\
Nicaragua & 1915 \\
Philippines & 95 \\
Russia & 3525 \\
United State & \\
\hline & \\
\hline & \\
\hline
\end{tabular}

The presence of aquifer and high geothermal gradient is not common occurrence in the crust. There are number of high geothermal resources which have high geothermal gradient but have no aquifer. There are few regions that have high geothermal gradient and aquifer and the geothermal rate of heat that is conducted through these regions represents a very small fraction of the global rate of 44TW, which is conducted from the Earth's core to the Earth surface and 
is produced mostly from the decay of radioactive elements in the core of the planet [1]. Most OECD countries have been utilized high temperature aqueous resources. After the utilization of these resources there is need to utilize and development of hot dry rock resources. Hot dry rock resources are most abundant resources on the planet. The next section elucidates the engineering method that could be used for the better exploitation of hot dry rock resources.

\section{Utilization of Hot, Dry Rock Heat}

Between the magma and earth surface there are rock formation at high temperature, but typically there are no aquifer to conduct the heat of the rock for the utilization of these geothermal resources (Table 2). For example there is multitude of location in USA, where the rock temperature at a depth of $3 \mathrm{~km}$ exceeds $175^{\circ} \mathrm{C}$ [8]. The concept of utilization of Earth's interior temperature in a thermodynamic cycle is very old (the high temperature heat in the interior $f$ earth and low temperature reservoir atmosphere may be combined in a thermodynamic cycle to produce electricity. The dry rock resources are abundant and do not exist at the tectonic plate boundaries but these resources have potential to generate enough power to satisfy the electricity needs of entire population of the world. However, there are some technological issues that have prevented us for realizing this type of technology.

Table 2. Powers produced from $60 \mathrm{~kg} / \mathrm{s}$ of geothermal fluid by a simple binary cycle and a binary-flashing cycle based on data from [10].

\begin{tabular}{ccccc}
\hline $\begin{array}{c}\text { Fluid } \\
\text { temperature } /\left({ }^{\circ} \mathrm{C}\right)\end{array}$ & $\begin{array}{c}\text { Power, } \\
\text { binary/kw }\end{array}$ & $\begin{array}{c}\text { Efficiency, } \\
\text { binary/\% }\end{array}$ & $\begin{array}{c}\text { Power, } \\
\text { binary-flashing/kw }\end{array}$ & $\begin{array}{c}\text { Efficiency, } \\
\text { binary-flashing/\% }\end{array}$ \\
\hline 90 & 432 & 5.7 & 546 & 5.8 \\
100 & 624 & 6.7 & 780 & 6.9 \\
110 & 852 & 7.6 & 1056 & 7.8 \\
120 & 1116 & 8.6 & 1374 & 8.7 \\
130 & 1416 & 9.4 & 1722 & 9.6 \\
140 & 1752 & 10.0 & 2118 & 10.3 \\
\hline
\end{tabular}

Many oil and gas fields with non producing wells (dry and abandoned wells) exist in the worldwide. These fields are not operational now but geological formations are well known. In the state of Texas (USA) more than 364,000 abandoned wells exists and of these wells at least 18,000 wells are deeper than 10,000 feet $(3 \mathrm{~km})[11]$ and a number of wells exist in the regions, where temperature is in between $\left(125^{\circ} \mathrm{C}-175^{\circ} \mathrm{C}\right)$. In this case technology problem is how to access the vast amount of energy at the depth of $3 \mathrm{~km}$ and produce electricity.

In order to extract the heat of rocks in the interior of Earth's crust, Davis and Michaelides [12] developed the concept of double pipe heat exchanger. They used organic fluid in the abandoned oil and gas wells and well become an annular heat exchanger, which is shown in Figure 3. 


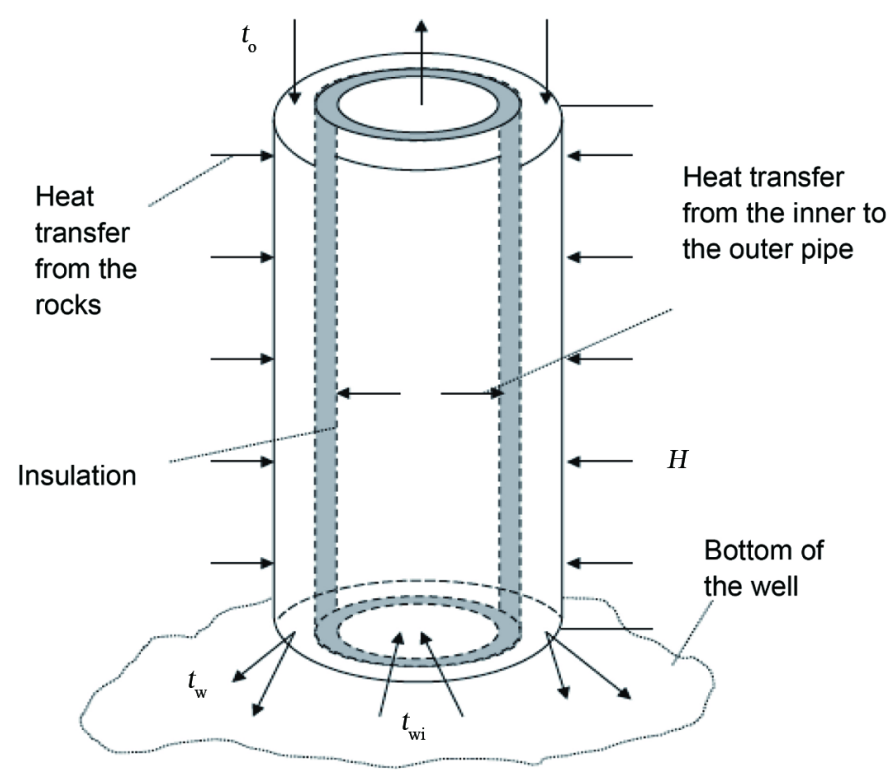

Figure 3. Schematic figure of the double-pipe heat exchanger for use of deep well.

The existing well is supplemented with an internal pipe carrying a minute amount of insulation. The cross-section of the well is composed of an outer annulus and a circular, inner core. Organic fluid is pumped down in the annuals of the well as the fluid goes down it absorbs heat from the surrounding rock and becomes hotter. Because of the action of gravity the pressure of organic fluid increases and as the fluid reaches the bottom of well, it is typically at super-critical state and start ascending in the inside section of the pipe. As the fluid moves upward pressure decreases continuously because the fluid movement is opposite to the gravitational force. The insulation of tubing prevents the exchange of heat between ascending and descending fluids. As during the ascending process pressure is lowered, the supercritical fluid becomes superheated vapor by the time it reaches the well head and should be fed directly to a turbine to produce electric power.

The amount of power produced by this type of abandoned and dry wells depends on numerous parameters [12]:

1) The outer diameter of well.

2) The inner diameter of pipe. The inner and outer diameter of well with injection velocity of organic fluid that is used for power production.

3) The injection pressure of organic fluid that influence the pressure of injection velocity as well as pressure of the exiting vapor.

4) The rock temperature of the well bottom.

5) The mass flow rate of the organic fluid that affect the power produced and heat transfer from the surrounding rock.

Figure 4 shows that the production of power of such type of heat exchanger as a function of injection pressure of fluid and dry rock temperature at the bottom of the well. 


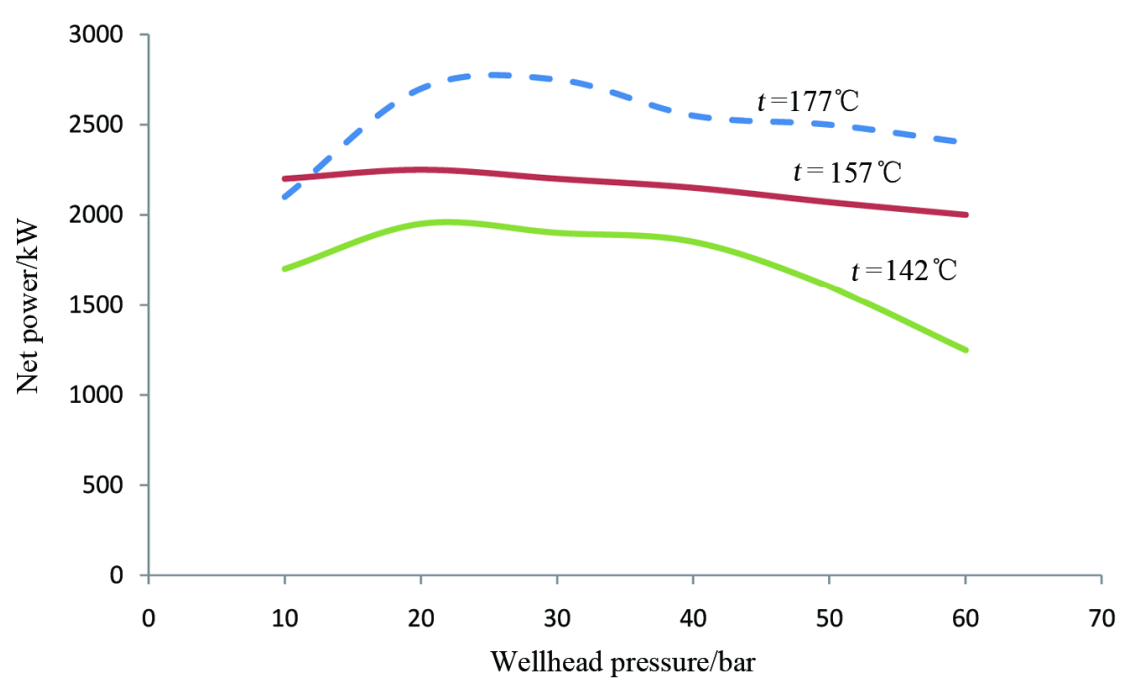

Figure 4. Net power produced by an outer diameter (12') well as a function of organic fluid injection pressure and bottom-hole temperature [12].

In Figure 4 it can be found that when bottom hole temperature decreases, the net power produce is also decreases because produce power depends on the temperature difference (Out let temperature-Inlet temperature) that is shown in the formula [10].

$$
P_{\text {net }}=\frac{m C_{\mathrm{p}}\left(t_{\text {out }}-t_{\text {in }}\right)\left(h_{1}-h_{2}\right)(1-X) \eta_{\mathrm{z}}}{2 r_{\mathrm{w}}}
$$

where $P$ is the actual power generated by the system, $\mathrm{W} ; \mathrm{m}$ is the mass flow rate of the fluid, $\mathrm{kg} \cdot \mathrm{s}^{-1} ; C_{p}$ is the specific heat of fluid, $\mathrm{J} /\left(\mathrm{kg} \cdot{ }^{\circ} \mathrm{C}\right) ; t_{\text {out }}$ is the outlet temperature of fluid at wellhead, ${ }^{\circ} \mathrm{C}$; $t_{\text {in }}$ is the Inlet temperature of fluid at wellhead, ${ }^{\circ} \mathrm{C}$; $h_{1}$ is the specific enthalpy of the fluid in the state $1, \mathrm{~J}^{\circ} \mathrm{kg}^{-1} ; h_{2}$ is the specific enthalpy of the fluid in the state $2, \mathrm{~J} \cdot \mathrm{kg}^{-1} ; \mathrm{X}$ is the proportion of electricity used by electric power plant, \%; $\eta_{\mathrm{z}}$ is unit efficiency, $\% ; r_{\mathrm{w}}$ is latent heat of vaporization, $\mathrm{kJ} / \mathrm{kg}$.

It is seen that a single 12 inch well may produce $2.5 \mathrm{MW}$ of electricity and if all the parameter are optimized, the well will produce close to $3.2 \mathrm{MW}$ [12]. the abrupt power drop when the injection pressure is lower than 10 bar and the bottom hole temperature is $450 \mathrm{~K}$, is due to chocking happening at the exit of the well, where sonic condition is established [13]. The extensive availability of hot rock resources implies that a large number of such wells and small scale of power plant should be constructed in a location to produce a significant amount of power.

This study was conducted [12] in a constant well temperature boundary condition. This is not a considerable impediment in the heating of organic fluid. Well should be constructed with large surface area or with a horizontal section which take out heat at the highest depth, where temperatures are highest. Such modification from the well design will permit the extraction of heat from deep, 
hot formations and the production of the supercritical organic fluid that becomes superheated vapor at the return path and drives the turbine at the well head [14] [15] [16].

\section{Conclusion}

The current study purposed that by utilizing abundant oil and gas well, the great amount of heat from the interior of the earth should be extracted and this heat have the potential to generate electric power for the entire population of the planet. The earth is a direct source of heat so heat power from the earth is constant, not periodically variable and should be utilized constantly to generate electric power. Most of the thermal energy is in the interior of the earth but not close to the aquifer so it is very important to utilize these dry rock resources. These geothermal resources are distributed on the earth and have the potential to generate high fraction of electric power. This new concept of double-pipe heat exchanger can extract a great deal of enthalpy from hot rock formations. Relevant studies indicate that a 12 inch double-pipe heat-exchanger, which penetrates to a depth of $3 \mathrm{~km}$, could extract sufficient energy to drive a $3.2 \mathrm{MW}$ turbine-generator system.

\section{References}

[1] Stathis, E.E. and Michaelide (2012) Alternative Energy Sources. Springer Berlin.

[2] Wight, N.M. (2015) Geothermal Energy from Abounded Oil and Gas Wells. Applied Thermal Engineering, 89, 908-915. https://doi.org/10.1016/j.applthermaleng.2015.06.030

[3] Geothermal Energy Association (2015) Annual US \& Global Geothermal Power Production Report. Geothermal Energy Association, Washington DC.

[4] Geothermal Energy Association (2008) Annual US Geothermal Power Production and Development Report. Geothermal Energy Association, Washington DC.

[5] Bu, X.B., Ma, W.B. and Li, H.S. (2012) Geothermal Energy Production Utilizing Abandoned Oil and Gas Wells. Renewable Energy, 41, 80-85.

https://doi.org/10.1016/j.renene.2011.10.009

[6] Michaelides, E.E. (2012) Entropy Production and Optimization of Geothermal Power Plants. Thermodynamic, 37, 233-246.

https://doi.org/10.1515/jnetdy-2011-0024

[7] Bertani, R. (2007) World Geothermal Generation in 2007. Proceeding European Geothermal Congress 2007, Geo-Heat Centre Quarterly Bulletin, Unterhaching, 30 May-1 June 2007, 28, 8-19.

[8] Tester, J.W. (2007) The Future of Geothermal Energy, Impact of Enhanced Geothermal System (EGS) on the United State in the $21^{\text {st }}$ Century: An Assessment by an MIT-Led Interdisciplinary Panel. Idaho National Laboratory, Report ISBN 0-615-13438-6, Idaho Falls.

[9] Geothermal Energy Association (2010)) Installed Generating Capacity, Geothermal Energy International Market Update. Holm A, Washington DC.

[10] Edrisi, B. and Michaelides, E.E. (2013) Effect of the Working Fluid on the Optimum Work of Binary-Flashing, Geothermal Power Plants. Energy, 38, 389-394. 
https://doi.org/10.1016/j.energy.2012.10.025

[11] Railroad Commission of Texas (2011) Oil and Gas Well Records. Austin, Texas.

[12] Davis, A. and Michaelides, E.E. (2009) Geothermal Power Production from Abandoned Oil Wells. Energy, 34, 866-872. https://doi.org/10.1016/j.energy.2009.03.017

[13] Kestin, J. (1980) A Source Book for the Production of Geothermal Electric Power. DOE, Washington DC.

[14] Brubacker, J. (2012) Numerical Simulation of Power Production of a Well Extracting Geothermal Energy and the Transient Thermal Response of the Surrounding Rock. Master's Thesis, University of Texas at San Antonio, San Antonio.

[15] Anderson, M.K. (2012) An Extended Sustainability Solution for Geothermal Energy Production from Abandoned oil and Gas Wells. Master's Thesis, University of Texas at San Antonio, San Antonio.

[16] Mehmood, A., Yao, J., Fun, D.Y. and Zafar, A. (2017) Geothermal Energy Potential of Pakistan on the Basis of Abandoned Oil and Gas wells. Journal of Petroleum \& Environmental Biotechnology, 7, 332. https://doi.org/10.4172/2157-7463.1000332 